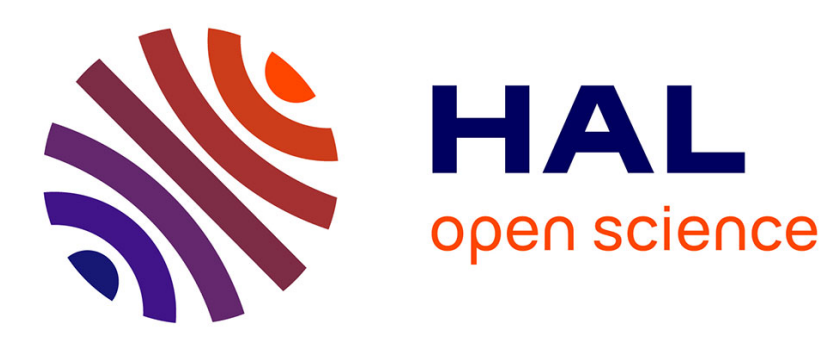

\title{
Impact Fracture Process and Mechanical Properties of Plain Concrete by Means of an Hopkinson Bar Bundle
}

\author{
C. Albertini, E. Cadoni, K. Labibes
}

\section{To cite this version:}

C. Albertini, E. Cadoni, K. Labibes. Impact Fracture Process and Mechanical Properties of Plain Concrete by Means of an Hopkinson Bar Bundle. Journal de Physique IV Proceedings, 1997, 07 (C3), pp.C3-915-C3-920. 10.1051/jp4:19973154 . jpa-00255443

\section{HAL Id: jpa-00255443 https://hal.science/jpa-00255443}

Submitted on 1 Jan 1997

HAL is a multi-disciplinary open access archive for the deposit and dissemination of scientific research documents, whether they are published or not. The documents may come from teaching and research institutions in France or abroad, or from public or private research centers.
L'archive ouverte pluridisciplinaire HAL, est destinée au dépôt et à la diffusion de documents scientifiques de niveau recherche, publiés ou non, émanant des établissements d'enseignement et de recherche français ou étrangers, des laboratoires publics ou privés. 


\title{
Impact Fracture Process and Mechanical Properties of Plain Concrete by Means of an Hopkinson Bar Bundle
}

\author{
C. Albertini, E. Cadoni and K. Labibes \\ European Commission, Joint Research Centre, Institute for Systems, Informatics and Safety, T.P. 480, \\ 21020 Ispra (VA), Italy
}

\begin{abstract}
The specimen size of concrete specimens should be large enough to be representative of the material. In this paper it is shown how the bundle bars method allows the dynamic mechanical characterisation by using the uniaxial elastic wave propagation theory used in the Hokinson bar technique.

Resumé: Pour le béton, la taille des echantillons à tester doit être assez large pour être representative du materiau. Pour cette raison, les tests à grandes vitesses de déformation n'ont pu être réalisés auparavant par la méthode des barres de Hopkinson. La méthode suggérée dans cette étude permet de passer outre cette difficulté. La barre est divisée en un faisceau de barreaux (multibarre) ce qui permet d'avoir la propagation uniaxiale des ondes et une sollicitation homogène sur la section transversale du materiau.
\end{abstract}

\section{INTRODUCTION}

A precise description of the mechanical characteristics and fracture process of plain concrete under high loading rate is of basic importance for the assessment of engineering structures against severe accidental loadings like those occurring in impacts, explosions and severe earthquakes. Such description must be gained from experiments performed on specimens of size sufficient to include aggregates of large size (at least $25 \div 30 \mathrm{~mm}$ ) in the plain concrete mix because results obtained on micro-concrete (aggregate size $5 \div 10$ $\mathrm{mm}$ ) can not be safely extrapolated to the large aggregate plain concrete of real civil engineering structures. Therefore, an experimental technique has been conceived and realised which foresees the high loading rate tensile testing of plain concrete cubes of $200 \mathrm{~mm}$ side with aggregate size of $25 \mathrm{~mm}$, by means of a Hopkinson Bar Bundle (HBB).

This paper describes the experiment and its capability of measuring the characteristics of the fracture process and the mechanical properties of plain concrete under high loading rate.

\section{EXPERIMENTAL TECHNIQUE}

The Hopkinson bar technique is a widely used technique to determine the mechanical properties of structural materials under high loading rates; while standard Hopkinson bars [1,2] with a diameter in the range of 10-20 mm are sufficient for dynamic testing of fine-grained materials like steel, larger bars are needed to load representative plain concrete specimen with real-size aggregates. Moreover, a special equipment is needed to allow the observation of the instantaneous distribution of stress and strain over the cross-section of large concrete specimens. Such distribution is in fact far from being homogeneous, due to the progressive cracking of the material during the loading process.

For the purpose of studying the dynamic properties of plain concrete, a special Hopkinson bar system (HBB) has been developed and installed in the Large Dynamic Testing Facility (LDTF) (Albertini-Montagnani $[3,4]$ ) of the Joint Research Centre at Ispra (Fig. 1). The HBB is a special equipment enabling the correct characterization of the stress-strain diagram. which is important for the 
evaluation of the energy absorption capability of the real plain concrete used in civil engineering structures. As shown in Fig. 1, the system consists of two bundles of 25 aluminum bars to which the concrete test specimen is glued using an epoxy resin. The bar bundles were constructed from two aluminum prismatic bars having a length of $2 \mathrm{~m}$ and a square section of $200 \mathrm{~mm}$ side subdivided by electroerosion into 25 symmetrical pairs of parallel bars for a length of $1 \mathrm{~m}$; the other $1 \mathrm{~m}$ length remains as a whole. In this way, concrete specimens with square cross section of $200 * 200 \mathrm{~mm}^{2}$ are tested and by instrumenting each individual bar in the bundle with strain gauges, measurement are obtained of the incident, reflected and transmitted pulses concerning the portion of the concrete specimen cross-section facing each symmetrical pair of bars in the bundle. Also the parts of the bar remained as a whole are instrumented with strain gauges in order to measure the incident, reflected and transmitted pulses acting on the whole cross section of the specimen.

The Hopkinson bar developed in our laboratory is different from the Hopkinson's device normally used in the material testing. In fact, in our device the mechanical pulse is generated by the sudden release of the energy stored in 32 cables of high strength steel and not by impacting projectile. Further, as Morse [5] has shown, the longitudinal wave propagation through a square section bar is equal to that in the cylindrical section.

A test with the LDTF-HBB is performed as follows:

1) a hydraulic actuator, of maximum loading capacity of $5 \mathrm{MN}$, is pulling 32 cables of high strength steel having a length of $100 \mathrm{~m}$; the pretension stored in these cables is resisted by one grounded explosive bolt in the blocking device (see Fig. 1);

2) second operation is the rupture of the explosive bolt which gives rise to a tensile mechanical pulse of 40 ms duration with linear loading rate during the rise time, propagating along the Hopkinson bar bundle and bringing to fracture the plain concrete specimen.

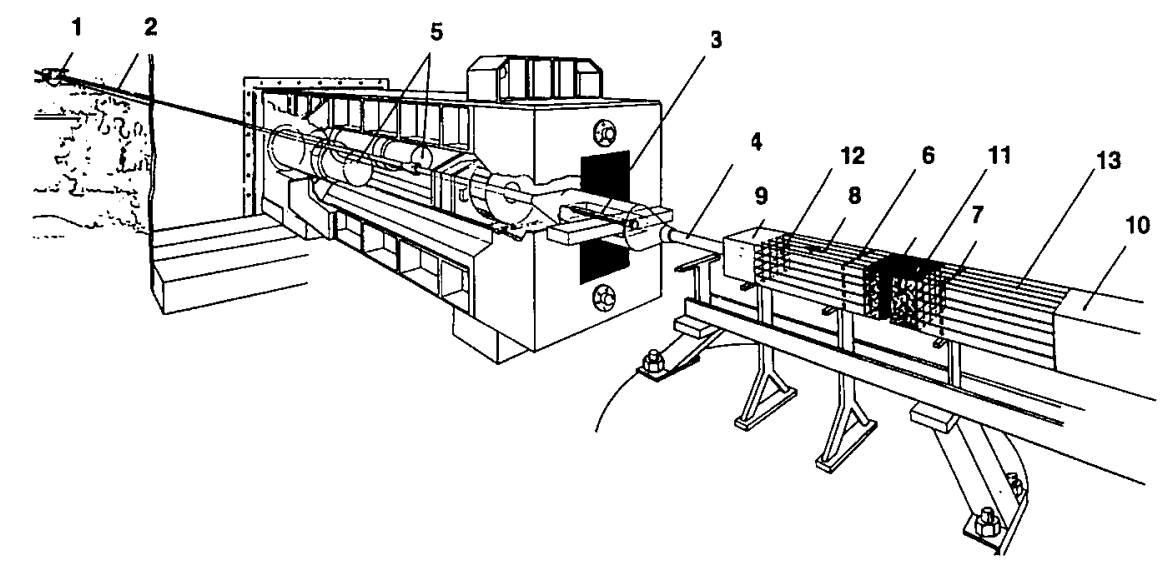

Figure 1: Experimental set-up - 1. hydraulic actuator; 2. high strength steel cables for energy storage (100m); 3. explosive bolt; 4 . loading bar; 5 . hydraulic dampers; 6 . strain gauges to measure incident and reflected pulses; 7 . strain gauges to measure transmitted pulses; 8. load direction; 9 . instrumented input whole aluminum bar; 10. instrumented output whole aluminum bar; 11. specimen; 12 elementary input bar bundle; 13. elementary output bar bundle.

The strain gauge stations on the incident whole bar and on the incident bar bundle measure the incident pulses $\varepsilon_{I}$ and the reflected pulses $\varepsilon_{R}$. The strain gauge stations on the transmitted whole bar and on the transmitted bar bundle measure the pulse $\varepsilon_{T}$ transmitted through the specimen. 


\section{IMPACT FRACTURE PROCESS OF PLAIN CONCRETE AT HIGH LOADING RATE}

It is well known that mechanical properties of concrete are strain-rate dependent so that the strength is higher at high loading rate. One important reason is the fracture phenomenon: in the static case the cracks follow the weaker aggregate-mortar interface, in the dynamic case the cracks propagate also through the hard aggregate. An other aspect is that in the dynamic case normally not only one crack is present but often it is present the phenomena of multiactivation of cracks. For these reason a local analysis of the specimen is essential and the HBB technique providesan answer to this necessity.

During the fracturing process each Nth pair of specular bars of the two bundles, which is individually instrumented with strain gauges, measures the incident, reflected and transmitted pulse $\varepsilon_{\mathrm{I}_{\mathrm{N}}}, \varepsilon_{\mathrm{R}_{\mathrm{N}}}, \varepsilon_{\mathrm{T}_{\mathrm{N}}}$, concerning only the portion of the specimen cross-section facing the cross-sections of this particular pair. It is postulated that during the fracturing process each pair of the specular bars of the bundles will be in one of the following physical situations (Albertini-Montagnani[4]):

1. Facing an uncracked portion of the specimen cross-section, therefore measuring a small relatively reflected pulse $\varepsilon_{R_{N}}$ and a large transmitted pulse $\varepsilon_{T_{N}}$ (situation 1 in Figs. 3-4).

2. Facing a semi-cracked portion of the specimen cross-section, therefore in the measurement situation where $\varepsilon_{R_{N}}$ is strongly increasing and $\varepsilon_{T_{N}}$ strongly decreasing (situation 2 in Figs. 3-4)

3. Facing a cracked portion of the specimen cross-section, therefore measuring a reflected pulse $\varepsilon_{R_{N}}$ of equal amplitude and of opposite sign to the incident pulse $\varepsilon_{I_{N}}$, while the correlated transmitted pulse decreases to $\varepsilon_{T_{N}}=0$ (situation 3 in Figs. 3-4)

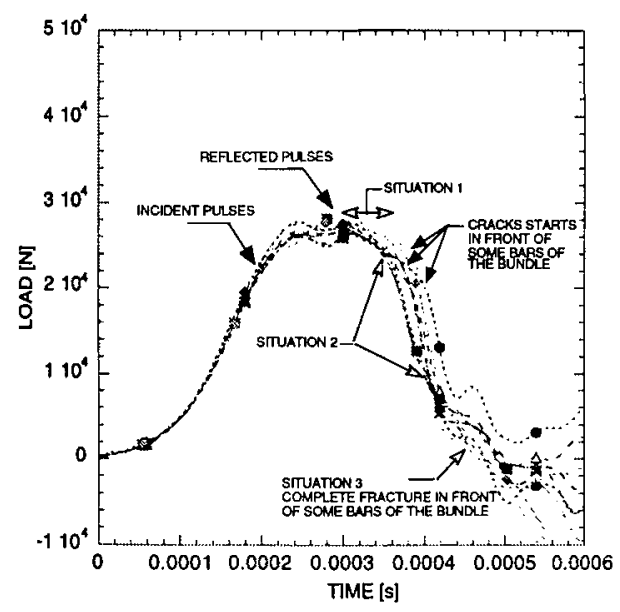

Figure 3: Record from input bars bundle correlation between reflected pulses and deformation - fracture phases

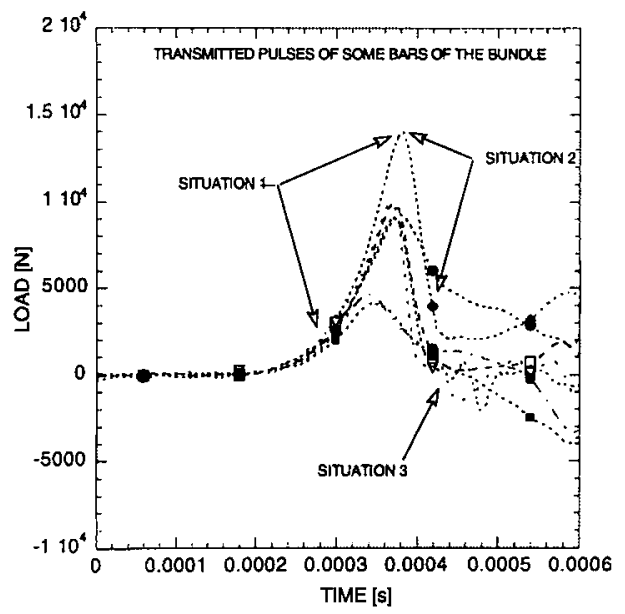

Figure 4: Record from output bars bundle; correlation between transmitted pulses and deformation - fracture phases

The beginning of the fracturing process has been considered the moment in which the first of the bars of the bundle shows the maximum load of the portion of the specimen cross-section facing it. In other word, the concrete part facing the Nth bar of the bundle begins to fracture when the corresponding transmitted pulse $\varepsilon_{T_{N}}$ reach its maximum and begins to decrease toward to be zero value. Figs 5-6 compare the time instants and the place of the specimen cross-section in which $\varepsilon_{\mathbb{T}_{N}}$ reaches its maximum, with the total load value. From this correlation established in Figs. 5-6 it can be seen that the fracturing process begins already in the ascending branch of the total load resisted by the specimen. 
Interesting correlations will be also possible by comparing the stress-strain diagrams obtained from each bar pair of the bundle with the morphology of the corresponding part of the specimen cross-section (e.g. mix percentages of mortar and aggregates).
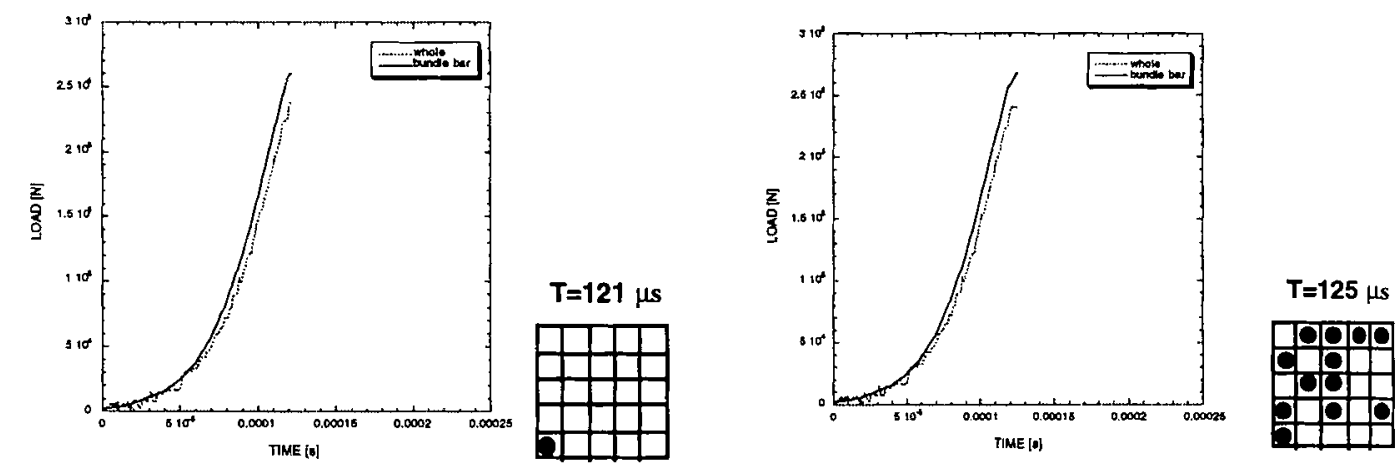

Figures 5-6: Total load vs. time curves of the bundle bar and whole bar compared with crack initiation when $\varepsilon_{T_{N}}=\max$

From this analysis (Albertini-Cadoni-Labibes [6]) can be seen that:

- in ten microseconds the crack initiation spreads over the whole specimen cross-section revealing the multiactivation mode of the fracture process;

- the initiation of the first crack at $121 \mu$ s corresponds to the begin of the loss of linearity of the ascending branch of the total loading;

- the spread time of the crack initiation over the whole cross-section (from 121 to $131 \mu \mathrm{s}$ ) corresponds to the begin of the total loading softening branch.

Taking into account the last observations it is possible to define a more refined analysis method for the construction of the true stress-strain diagram starting from the bar bundle records. This refined method introduces for each elementary bundle bar an evaluation of the residual resisting cross-section $\mathrm{A}_{\text {TRUE }}$ of the Nth facing part of the concrete specimen by decreasing the initial value $A_{0}$ of an amount taking into account the separation due to the crack propagation.

\section{DEFINITION OF THE TRUE STRESS-STRAIN CURVES}

The stress-strain curve has been constructed in two different modes. The first mode included: the stress measured from the transmitter whole bar and the strain recorded from the direct measurement on the specimen by means of the electro-optical device. The second mode included: the stress measured from the transmitter bundle bars, as the average of these, and the strain as the average of the strains calculated from the reflected waves measured in the incident bundle bars. This second mode of construction of the stressstrain curve is explained below. The instantaneous values of the stress and strain of the concrete facing the Nth elementary Hopkinson bar of the bundle are obtained by the following equations; which are those of the classical Hopkinson's theory [1,2]:

$$
\sigma_{N}(t)=\frac{A_{N} \cdot E \cdot \varepsilon_{T_{N}}(t)}{A_{0}} \quad(1) ; \quad \varepsilon_{N}(t)=\frac{2 C}{L_{0}} \int_{0}^{t} \varepsilon_{R_{N}}(t) d t
$$

where: $A_{N}=$ cross-section of the elementary aluminum bar; $A_{0}=$ cross-section of the concrete facing the elementary Hopkinson bar; $\mathrm{E}=$ Young modulus of aluminum; $\mathrm{t}=$ time; $\mathrm{C}=$ elastic wave speed in aluminium; $\mathrm{L}_{\mathrm{O}}=$ length of the concrete specimen. 
During the test time the fractured parts of the specimen cross-section reduce to zero the records $\varepsilon_{\mathrm{T}_{\mathrm{N}}}$ (or $\varepsilon_{R_{N}}=-\varepsilon_{I_{N}}$ ) of the facing transmitter bars of the bundle and therefore the corresponding values of eq.(1); then, we can assume as first approximation that the true stress and true strain of the specimen are given by the average of the stresses and strains of the $\mathrm{X}$ bars of the bundle where $\varepsilon_{\mathrm{T}_{N}} \neq 0$ as follows:

$$
\sigma_{\text {TRUE }}(t)=\frac{\frac{\sum_{1}^{X} A_{N} \cdot E \cdot \varepsilon_{T_{N}}(t)}{A_{0}}}{X}
$$

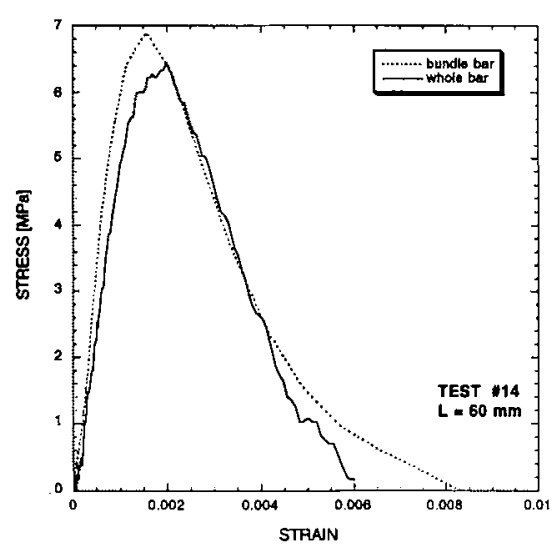

Figure 6: Comparison between the stress vs. strain curve of plain concrete calculated in two different modes
$(3) ; \varepsilon_{T R U E}(t)=\frac{\sum_{1}^{X} \frac{2 C}{L_{0}} \int_{0}^{t} \varepsilon_{R_{N}}(t) d t}{X}$

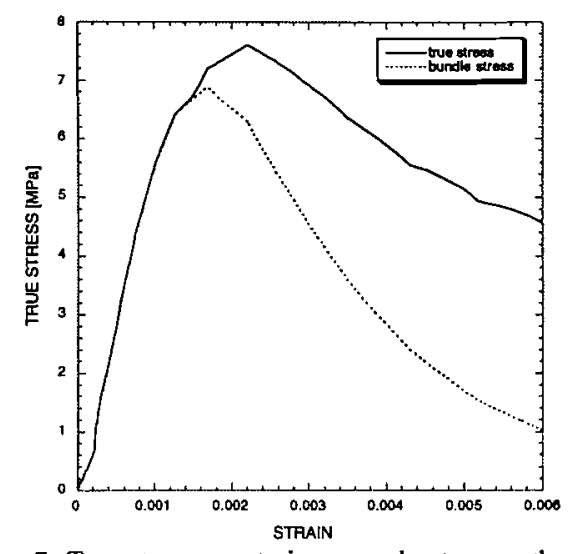

Figure 7: True stress vs. strain curves by two methods of bar bundle analysis. Specimen \#14

The stress-strain curves reconstructed following the two modes (whole bar and bundle bar records) described before are compared in Fig. 6. It can be seen that they differ moderately because the ultimate strength and the last part of the softening branch of the stress-strain curve reconstructed with the bar bundle analysis are higher than those reconstructed with the whole bar analysis. This difference is due to the more detailed analysis allowed by the bar bundle method; the difference is moderate because the fracture starts simultaneously in many points of the cross section of the specimen as it has been shown before. The strain rate of the tests was $10 \mathrm{~s}^{-1}$.

For the estimation of $\mathrm{A}_{\mathrm{TRUE}}$, defined as the residual resisting cross-section of the Nth part of the total specimen cross-section, a signal of a generic transmitter bundle bar is considered where it is possible to recognize two important points. The points $t_{1}$ and $t_{2}$, which represent the times when the signal $\varepsilon_{T_{N}}$ reaches the maximum and the zero value respectively. It is hypothesized that during the $\Delta t=t_{1}-t_{2}$ time interval the residual resisting cross-section $\mathrm{A}_{\text {TRUE }}$ decreases linearly with time $t$ from the initial value $\mathrm{A}_{0}$ to zero. This decrease is given by a linear function of time $f_{N}(t)$ :

$$
f_{N}(t)=1-\frac{t-t_{1}}{t_{2}-t_{1}} \quad \text { with } t_{1} \leq t \leq t_{2}
$$

Therefore the total residual resisting cross-section of the specimen and the total load $\mathbf{P}_{\text {true }}$ from the bundle bars are given by:

$$
A_{\text {true }}=\sum_{N=1}^{25} A_{0} \cdot f_{N}(t) \quad(5) \quad ; \quad P_{\text {true }}=\sum_{N=1}^{25} A_{N} \cdot E \cdot \varepsilon_{T_{N}}
$$


where: $A_{N}=$ cross-section area of an elementary aluminum bundle bar; $E$ = aluminum elastic modulus; $\varepsilon_{\mathrm{T}_{\mathrm{N}}}=$ transmitted pulse in an elementary bar bundle.

Then, the true stress $\sigma_{\text {true }}$ of concrete is calculated as follows:

$$
\sigma_{\text {true }}=\frac{P_{\text {true }}}{A_{\text {true }}}=\frac{\sum_{N=1}^{25} A_{N} \cdot E \cdot \varepsilon_{T_{N}}}{\sum_{N=1}^{25} A_{0} \cdot f_{N}(t)}
$$

In this refined method of true stress-strain diagram construction the strain continues to be calculated following equation (4). In Fig. 8 the true stress-strain curves are shown. The curve indicated in figure with solid line has been obtained with the refined analysis method by application of the equation (7) and (4) to the records of the bar bundles while that indicated with the dotted line has been obtained by the application the equations (3) and (4). The comparison shows that the refined analysis method of the bar bundle records gives a more precise definition of the softening branch of the stress-strain diagram of concrete and therefore of the energy absorption capability of this material during fracture.

We remaind here that the static maximum strength of the plain concrete used in these experiments was about $3 \mathrm{MPa}$ confirming the marked increase of strength with increasing loading rate

\section{CONCLUSIONS}

The HBB technique allows more accurate definition of the stress-strain diagram of plain concrete including the softening branch leading to fracture. In fact, it has been measured step by step: the true resisting crosssection and the load acting on that cross-section; the displacement given by the deformation of the true resisting cross-section; the crack propagation path and speed.

These parameters allowed a reconstruction of the true stress-strain diagram and of the fracture process of the material up to complete separation of the specimen in two halves.

It has also been shown that by this technique it is possible to follow in detail the impact fracture propagation process and to correlate local morphology of the specimen with the local measurement of mechanical characteristics.

The present results are part of a larger research programme which includs also the study of relative humidity effects and the compression dynamic loading.

\section{References}

[1] Davies R.M., A Critical Study of the Hopkinson Pressure Bar, Phil. Trans.Roy. Soc., London, Ser. A, (1948) 240-375.

[2] Lindholm U.S., High Strain Rate Test, Techinque of Metals Research (Wiley),Vol. 5 (1971), Part. 1.

[3] Albertini C., Montagnani M., Testing Technique in Dynamic Biaxial Loading, (Institute of Physics, London) Conf.Ser.No. 47, (1979) 25-34.

[4] Albertini C., Montagnani M., Study of the true tensile stress-strain diagram of plain concrete with real size aggregate; need for and design of a large Hopkinson bar bundle, J. de Physique IV, 4, sept.' $94, \mathrm{C}$. 113-118.

[5] Morse, R. W., J. Acoust. Soc Amer., (1948), 20, 833.

[6] Albertini C., Cadoni E., Labibes K., Dynamic mechanical behaviour of large concrete specimen by means of a bundle Hopkinson bars, Proc. 2nd ISIE:, Beijing. (1996) pp. 214-219. 